\title{
Ion Peak Narrowing by Applying Additional AC Voltage (Ripple Voltage) to FAIMS Extractor Electrode
}

\author{
Viktor V. Pervukhin and Dmitriy G. Sheven \\ Institute of Inorganic Chemistry, Siberian Branch, Russian Academy of Sciences, Novosibirsk, Russia
}

The use of a non-uniform electric field in a high-field asymmetric waveform ion mobility spectrometry (FAIMS) analyzer increases sensitivity but decreases resolution. The application of an additional AC voltage to the extractor electrode ("ripple" voltage, $U_{\text {ripple }}$ ) can overcome this effect, which decreases the FAIMS peak width. In this approach, the diffusion ion loss remains minimal in the non-uniform electric field in the cylindrical part of the device, and all ion losses under $U_{\text {ripple }}$ occur in a short portion of their path. Application of the ripple voltage to the extractor electrode is twice as efficient as the applying of $U_{\text {ripple }}$ along the total length of the device. (J Am Soc Mass Spectrom 2010, 21, 47-52) (C) 2010 American Society for Mass Spectrometry

0 tudies using high-field asymmetric waveform ion mobility spectrometry (FAIMS) have become quite common [1, 2]. The use of a non-uniform electrical field in such devices increases sensitivity (due to decreased diffusion loss of ions in the analytical gap) but decreases resolution $[3,4]$. This is because at a given dispersion voltage, $U_{D}(t)$, there is a whole set of compensation voltage values, $\delta U_{c}$, which make it possible to focus ions at different parts of the analytical gap [5].

Applying numerical modeling, Shvartsburg et al. [6] showed that adding to $U_{D}(t)$ a "noise" (electronic noise at random frequencies - "white noise") or "ripple" (fixed frequency) voltage narrows the ion focusing region while ions pass through a cylindrical FAIMS. This makes it possible to improve the device resolution at the price of decreasing the sensitivity. However, Shvartsburg et al. did not consider ion transit in the region of the hemispheric tip of the FAIMS inner electrode. The advanced cylindrical devices (for example, all commercial platforms by Thermo Fisher) have no hemispheric tip on the inner electrode for the outlet of ions; however, such a method of ion extraction with a hemispheric tip is still used.

The parameters of the region near the hemispheric tip of the FAIMS inner electrode affect the resolution and sensitivity of the FAIMS analyzer and, therefore, they must be optimized to improve FAIMS analytical response. The experimental results obtained from the FAIMS analyzer with a hemispheric tip on the inner electrode are equivalent to the results for ion separation in two different tandem FAIMS instruments. The initial separation occurs across the cylindrical part of the elec-

Address reprint requests to Dr. V.V. Pervukhin, Institute of Inorganic Chemistry, Siberian Branch, Russian Academy of Sciences, Ak.Lavrentev's Avenue 3, 630090 Novosibirsk, Russia. E-mail: pervv@che.nsk.su trodes; the final separation occurs around the inner electrode tip. The ion transit windows in the two FAIMS instruments can coincide, but not completely [7]. Moreover, an ion trap arises near the hemispheric tip of the inner electrode at atmospheric pressure [8,9]; this trap can also affect FAIMS resolution and sensitivity [10].

Based on these previous articles, we tried to optimize FAIMS operation in terms of sensitivity and resolution by applying the ripple voltage not as an increment to the dispersion voltage along the ion total pathway length in FAIMS, but only at the end of it, to the hemispheric electrode of the ion inlet to the mass spectrometer. The idea is to have minimal diffusion ion loss in the cylindrical part of the device (and thereby retain high sensitivity) and to narrow the ion transit interval $\delta U_{c}$ in the cylindrical FAIMS in the end of the device, increasing the resolution. We have partly verified the idea and briefly reported it in [11].

\section{Experimental}

\section{FAIMS}

Figure 1 illustrates a general overview of the FAIMSmass spectrometer experimental setup in which the FAIMS has a hemispheric-tipped inner cylindrical electrode (1), an outer electrode (2) with a cylindrical inner surface, and an extractor electrode (3) as a hollow hemisphere around the tip of the inner electrode. In our experiments, we used an inner electrode with an outside diameter (o.d.) of $7.4 \mathrm{~mm}$, terminating in a hemisphere of the same diameter; an outer electrode with an inner diameter (i.d.) of $10.6 \mathrm{~mm}$; and an extractor electrode with the same diameter as the inner hemisphere. The outer and extractor electrodes were electrically insulated from each other and from the inlet 


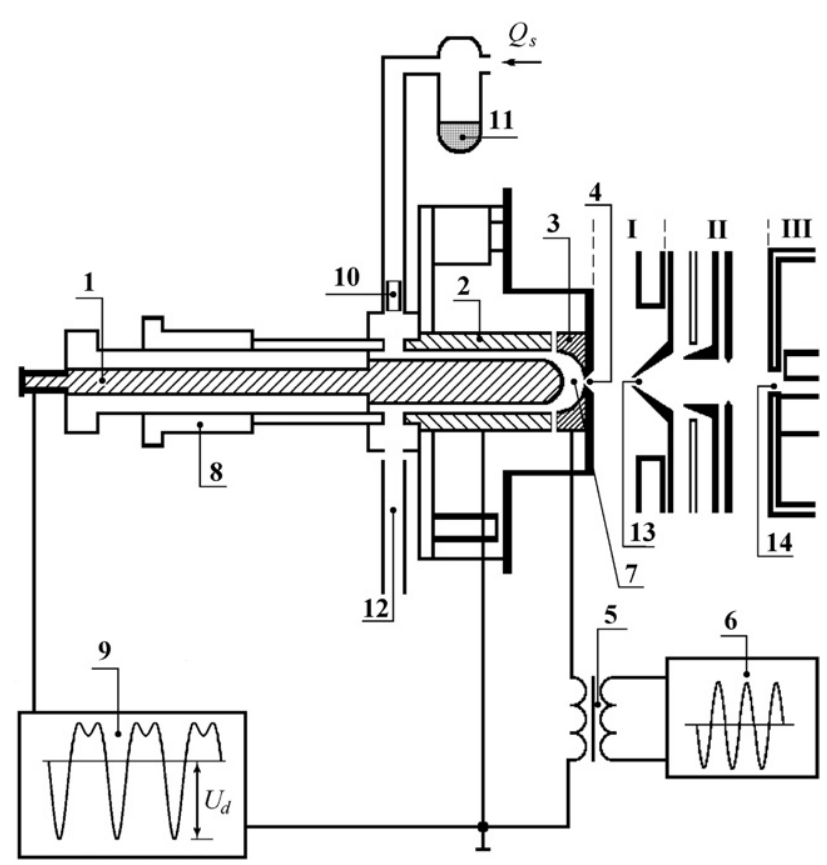

Figure 1. The experimental setup and the circuit connecting the ripple voltage to the FAIMS analyzer. 1, 2, and 3: FAIMS inner, outer, and extractor electrodes, respectively; 4 : the mass spectrometer inlet orifice; 5 : the transformer generating $U_{\text {ripple }}$; 6 : the low-frequency generator; 7: variable spacing between the FAIMS inner and extractor electrodes; 8: the screw mechanism for adjusting the spacing; 9: the asymmetric voltage generator; 10: the ionization chamber; 11: the test compound; 12: the carrier gas flow; 13: the skimmer; and 14: the mass analyzer inlet opening.

orifice of the mass spectrometer (4) (diameter of 0.3 $\mathrm{mm}$ ). This design makes it possible to apply the ripple voltage produced by transformer (5) to the extractor electrode (as shown in the figure) or to the outer electrode. The transformer primary coil is connected to a G3-118 low-frequency generator (6) (Radiopribor Co., Velikie Luki, Pskovskaya obl., Russia). The generator frequency range is $10 \mathrm{~Hz}$ to $100 \mathrm{kHz}$; the maximum output signal level is $10 \mathrm{~V}$. The transformer was chosen to avoid introducing distortions to the waveform and level of the generator signal. As a result, ripple voltage arose in the secondary coil, $U_{\text {ripple }}$ (from 0 to $200 \mathrm{~V}$ ) with the frequency $\omega_{\text {ripple }}$ (from $100 \mathrm{~Hz}$ to $100 \mathrm{kHz}$ ), sinusoidal. The waveform of the signal and its voltage were controlled by an S1-137 oscilloscope (BELVAR, Minsk, Belarus) connected in parallel with the secondary coil of the transformer (not shown in the figure).

The spacing between the inner and extractor electrodes, $X$ (7), is adjusted by a screw device (8) and can be varied from 0 to $10 \mathrm{~mm}$. The total ion pathway length from the ion inlet orifice to the ion outlet was about $50 \mathrm{~mm}$.

The FAIMS ion separation chamber operates at room temperature, and its electrodes are fed by an asymmetric voltage generator (9) that also produces compensation voltage. The parameters of the asymmetric voltage generator are: bisinusoidal voltage (shown graphically in Figure 1 by a box depicting the asymmetric voltage generator); maximum generated peak voltage, $3.6 \mathrm{kV}$; and asymmetric voltage frequency, $170 \mathrm{kHz}$. The waveform and amplitude of the asymmetric voltage $U_{D}(t)$ were also controlled by the S1-137 oscilloscope.

Ions in the investigation were produced in an ionization chamber (10) that was a cylindrical space of 5 $\mathrm{mm}$ i.d. and $10 \mathrm{~mm}$ long. The space was equipped with a ${ }^{63} \mathrm{Ni} \beta$-radiation source (Izotop, St. Petersburg, Russia) with an activity of $10 \mathrm{mCi}$. The gas investigated was injected into the chamber by means of a test junction (11) at a flow rate of $Q_{s}=0.1 \mathrm{~L} / \mathrm{min}$ and was ionized. Traces of impurities (e.g., steam) in the carrier gas flow exert a negative effect on separation of the ions and transfer through FAIMS. For this reason, the carrier gas (air) (12), which was supplied into the mixing chamber at a flow rate of about $5 \mathrm{~L} / \mathrm{min}$, as is shown in Figure 1 (excess carrier gas was expelled into the gap between the inlet tube and the mixing chamber), was first refined by passing through a silica gel column of $50 \mathrm{~mm}$ i.d. and $300 \mathrm{~mm}$ high. As was shown previously [12], the presence of ethanol vapor in the carrier gas leads to an increasing peak shift of the target substance in the FAIMS spectrometer; hence, after refining, the carrier gas was saturated with ethanol vapor. This was also done for to minimize the impact of water steam on the behavior of ions, because effects of water steam in these conditions decreases at presence of ethanol vapor [12].

A carrier gas flow of about $3 \mathrm{~L} / \mathrm{min}$ carries the ions along the FAIMS analyzer region and transports them into the vacuum system of the mass spectrometer. The ions are first separated in the annular gap of $1.6 \mathrm{~mm}$ width between the concentric cylinders of the inner and outer electrodes, where the electrode surfaces are parallel. The ions that have passed along the first parallel region enter into the second region between the domed tip of the inner electrode and the extractor electrode, and go out for MS analysis through the inlet orifice (4).

\section{Mass Spectrometer}

We have described a mass spectrometer with ionization at atmospheric pressure [13]. In brief, the system is a three-stage differential pumping system (Figure 1). In the first stage (I), pumped by a fore pump with a capacity of $5 \mathrm{~L} / \mathrm{s}$ to $500 \mathrm{~Pa}$, the ions delivered to the inlet orifice are focused onto the skimmer orifice (13) ( $0.3 \mathrm{~mm}$ in diameter) and enter into the second differential pumping stage (II). This stage is pumped by a turbomolecular pump with a capacity of $100 \mathrm{~L} / \mathrm{s}$ to $10^{-1}$ $\mathrm{Pa}$, and thus it becomes possible to apply an electric ion focusing system and focus the ions onto the inlet opening of the mass analyzer (14). An MX-7304A monopole mass analyzer is situated in the third differential pumping stage (III), which is pumped by a turbomolecular pump with a capacity of $100 \mathrm{~L} / \mathrm{s}$ to vacuum of $10^{-4} \mathrm{~Pa}$, sufficient for normal operation of the analyzer and the ion registration system. 


\section{Chemicals}

The chosen test substances were: diethylamine $\left(\left(\mathrm{C}_{2} \mathrm{H}_{5}\right)_{2} \mathrm{NH}\right.$, molecular weight 73); aniline $\left(\mathrm{C}_{6} \mathrm{H}_{5} \mathrm{NH}_{2}\right.$, molecular weight 93); $\mathrm{N}, \mathrm{N}$-diethylacetamide $\left(\mathrm{CH}_{3} \mathrm{C}(\mathrm{O}) \mathrm{N}\left(\mathrm{C}_{2} \mathrm{H}_{5}\right)_{2}\right.$, molecular weight 115); $\mathrm{N}, \mathrm{N}$-diethylaniline $\left(\mathrm{C}_{6} \mathrm{H}_{5} \mathrm{~N}\left(\mathrm{C}_{2} \mathrm{H}_{5}\right)_{2}\right.$, molecular weight 149); and triamilamine $\left(\left(\mathrm{C}_{5} \mathrm{H}_{11}\right)_{3} \mathrm{~N}\right.$ molecular weight 227). These substances yield in the mass spectrum a steady-registered peak with a high sensitivity, well separated from the background peaks with a mass corresponding to the $(\mathrm{M}+\mathrm{H})^{+}$ion. All test compounds of high-purity grade were supplied by Ekos-1 Co., Moscow, Russia, and before use they were distilled once to eliminate impurities formed as a result of their oxidation during storage.

\section{Results and Discussion}

We will begin with two important comments. First, the impact of $U_{\text {ripple }}$ and $1 / \omega_{\text {ripple }}$ in all our experiments was equivalent, i.e., we can achieve identical effects by varying these two parameters in the same manner. For this reason, we fixed $\omega_{\text {ripple }}$ for all the experiments and varied only $U_{\text {ripple. }}$. Thus, $\omega_{\text {ripple }}$ is equal to $2 \times 10^{3} \mathrm{~Hz}$ everywhere in this report, unless otherwise specified. Second, for all the investigated compounds, i.e., diethylamine, aniline, $\mathrm{N}, \mathrm{N}$-diethylacetamide, $\mathrm{N}, \mathrm{N}$-diethylaniline, and triamilamine, the effects of $U_{\text {ripple }}$ are qualitatively similar. For this reason, throughout the paper we illustrated the relevant effect on one of the compounds, assuming that the others behave similarly.

The effect of the ripple voltage applied to the FAIMS extractor electrode on the form of the peak for the protonated ion of aniline, $\mathrm{H}^{+}\left(\mathrm{C}_{6} \mathrm{H}_{5} \mathrm{NH}_{2}\right)$, is shown in Figure 2. In the experiment, we scanned the compensation voltage $\left(U_{c}\right)$ at dispersion voltages, $U_{d}$ of $3.13 \mathrm{kV}$, and the mass spectrometer was set in such a manner that it followed only the peak $\mathrm{m} / \mathrm{z}=94$ corresponding

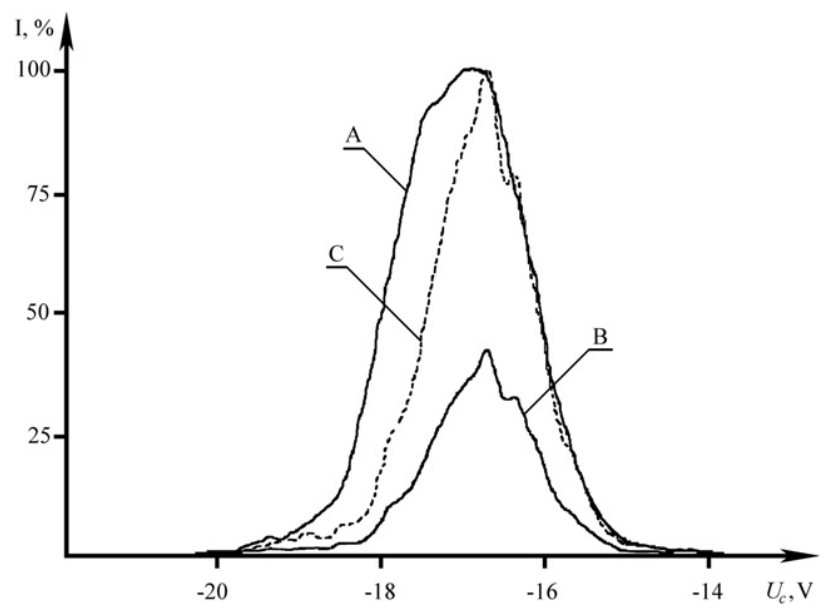

Figure 2. The effect of $U_{\text {ripple }}$ (applied to the FAIMS extractor electrode) on the signal waveform of protonated aniline ion $\mathrm{H}^{+}\left(\mathrm{C}_{6} \mathrm{H}_{5} \mathrm{NH}_{2}\right)$. A: $U_{\text {ripple }}=0 \mathrm{~V}$; B: $U_{\text {ripple }}=10 \mathrm{~V}$; C: B spectrum enhanced to the same intensity as $\mathrm{A}$. $U_{d}=3.13 \mathrm{kV}$; the spacing between the extractor and inner electrodes is $X=3.3 \mathrm{~mm}$. to the protonated aniline ion. In Figure 2, spectra A and B show the experimental results without processing, as they were obtained. It is seen that upon applying the voltage $U_{\text {ripple }}=10 \mathrm{~V}$ to the extractor electrode (spectrum $\mathrm{B})$, the $\mathrm{H}^{+}\left(\mathrm{C}_{6} \mathrm{H}_{5} \mathrm{NH}_{2}\right)$ ion signal decreased by approximately half (compared to spectrum A, where $U_{\text {ripple }}=0 \mathrm{~V}$ ). At the same time, if we reduce both signals to equal intensity, as is shown in Figure 2 by a dashed line, spectrum C, it can be seen that the width of the FAIMS peak of the protonated aniline ion has decreased.

The signal narrowing in Figure 2 occurred asymmetrically: the right-hand front of the signal remained in the same place, while the left-hand front shifted. Contrary to this result, numerical modeling in [10] showed that adding the ripple voltage to $U_{D}(t)$ along the total ion pathway length would lead to symmetrical narrowing of the focusing region and, therefore, to symmetrical narrowing of the FAIMS peak. The lefthand front of the peak in Figure 2 corresponds to ion transit near the inner electrode $[9,15]$. Therefore, in our experiments, the ripple voltage slightly affects the transit of ions far from the inner electrode.

This is in agreement with the results in article [11], where the authors showed that a cylindrical FAIMS with a hemispheric inner electrode operates like a tandem FAIMS: the first separation happens along the cylindrical part of the electrodes, and the second separation occurs around the tip of the inner electrode, the ion transit window in the spherical part being somewhat wider. Thus, the transit window of the spherical FAIMS near the extractor electrode is not filled with ions, and the impact of $U_{\text {ripple }}$ is negligible.

If this is true, the location of the inner electrode must affect the peak narrowing. Figure 3 shows relative narrowing of the FAIMS peak width of the protonated aniline ion, $\mathrm{H}^{+}\left(\mathrm{C}_{6} \mathrm{H}_{5} \mathrm{NH}_{2}\right)$, as a function of the spacing between the inner and extractor electrodes. Here, $\Delta$ is the peak's full width at half-maximum (FWHM), and $X$ is the spacing between the inner and extractor electrodes (see Figure 1).

The two curves in Figure 3 were obtained for different values of the dispersion voltage $\left(U_{d}=3.13\right.$ and 2.35 $\mathrm{kV}$ for curves $\mathrm{A}$ and $\mathrm{B}$, respectively). By varying $U_{d}$, we obtained different values of $U_{c}(-17$ and $-8.5 \mathrm{~V})$. In spite of this fact, it can be seen from Figure 3 that there is an optimum spacing between the extractor and inner electrodes when the narrowing effect is maximum, and the spacing depends slightly on these parameters. Such an optimum in the region $X=4 \div 6 \mathrm{~mm}$ exists for all of the investigated compounds, but the intensities of peaks vary over this interval. For this reason, in all experiments described below, we varied $X$ in that region, setting $X$ to the value producing the maximum signal intensity.

The slight effect of FAIMS peak narrowing at large spacings between the inner and extractor electrodes is caused by the decreasing intensity of the electric field generated by $U_{\text {ripple. }}$. The operating value of the ripple 


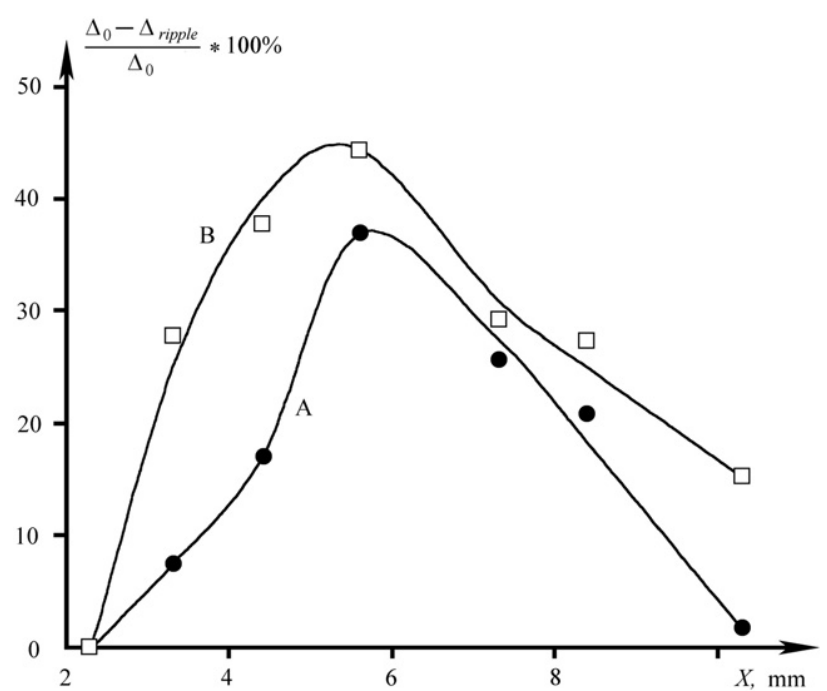

Figure 3. FAIMS peak narrowing of $\mathrm{H}^{+}\left(\mathrm{C}_{6} \mathrm{H}_{5} \mathrm{NH}_{2}\right)$ ion as a function of spacing between extractor and inner electrodes, $X$ (see Figure 1) with $U_{\text {ripple }}=30 \mathrm{~V}$ applied to the extractor electrode; $\Delta_{0}$ and $\Delta_{\text {ripple }}$ are the peak FWHM with and without applied ripple voltage, respectively. Curve A (filled circles): $U_{d}=3.13 \mathrm{kV}$ and $U_{c}=$ $-17 \mathrm{~V}$. Curve B (open squares): $U_{d}=2.35 \mathrm{kV}$ and $U_{c}=-8.5 \mathrm{~V}$.

electric field $E_{\text {ripple }} \sim U_{\text {ripple }} / X$ decreases rapidly as $X$ grows.

The mechanism of decreasing the narrowing effect from the side of small $X$ is more complicated, although the effect will obviously be absent if the amplitude of ion oscillations under the dispersion voltage, $U_{d}$, is comparable with the size of the gap between the inner and extractor electrodes. In this case, the voltage $U_{\text {ripple }}$ narrows only the signal intensity, but does not narrow the peak because the interval $\delta U_{c}$, corresponding to the ion transit at this value of $U_{d}$, narrows to the unique $U_{c}$ at which this transit is possible.

The stated aim of our work is to decrease the ion diffusion loss for FAIMS by applying ripple voltage $U_{\text {ripple. }}$. We hypothesized that if one applies the ripple voltage, not as an increment to the dispersion voltage along the ion total pathway in FAIMS, but only at the end of it, to the hemispheric electrode of ion inlet into the mass spectrometer, then the ion diffusion loss remains minimal in the cylindrical part of the device, but the peak becomes narrower in the region of the hemispheric tip of the inner electrode where the diffusion loss is less. In this context, it is of interest to compare the FAIMS peak narrowing effect upon applying $U_{\text {ripple }}$ with the outer electrode (i.e., by acting on the ions practically along the whole pathway to FAIMS) and upon applying $U_{\text {ripple }}$ to the extractor electrode at spacings between the extractor and inner electrodes that yield the maximum narrowing effect.

Figure 4 illustrates the reduction of the FAIMS peak width of protonated triamilamine ion, $\mathrm{H}^{+}\left(\mathrm{C}_{5} \mathrm{H}_{11}\right)_{3} \mathrm{~N}$, as a function of its intensity. Curves $\mathrm{A}$ and $\mathrm{B}$ correspond to $U_{\text {ripple }}$ applied to the extractor electrode and the outer electrode, respectively.
As can be seen, upon applying $U_{\text {ripple }}$ both to the outer and extractor electrodes, we observe narrowing of the $\mathrm{H}^{+}\left(\mathrm{C}_{5} \mathrm{H}_{11}\right)_{3} \mathrm{~N}$ peak and a simultaneous drop of its intensity. From the viewpoint of the peak narrowingto-intensity decrease ratio, applying the ripple voltage to the extractor electrode is more effective: the curve A passes above the curve B everywhere. On average, this difference is about a factor of two, which validates the idea that applying $U_{\text {ripple }}$ to the extractor electrode to reduce the time of its action on the ions and decrease the diffusion loss is quite vital.

Figure 5 shows the variation of FAIMS signal intensity as a function of applied ripple voltage for protonated diethylamine ion, $\mathrm{H}^{+}\left(\left(\mathrm{C}_{2} \mathrm{H}_{5}\right)_{2} \mathrm{NH}\right.$, for two different values of the dispersion voltage, $U_{d}$ (curve $\mathrm{A}, U_{d}=$ $2,035 \mathrm{kV}$; curve $\mathrm{C}, U_{d}=1,57 \mathrm{kV}$; the corresponding compensation voltages, $U_{c}=-7.5$ and $\left.-3.5 \mathrm{~V}\right)$. Figure 5 also represents the peak narrowing at half-maximum (as a percentage) as a function of applied ripple voltage (curves $\mathrm{C}$ and $\mathrm{D}$ for $U_{d}=2.035 \mathrm{kV}$ and $1.57 \mathrm{kV}$, respectively). It can be clearly seen that the peak width cannot decrease indefinitely with the application of $U_{\text {ripple }}$ : at some $U_{\text {ripple }}$, the peak width ceases to narrow even as the signal intensity still decreases. In fact, when the value of $U_{d}$ is high, the achievement of a constant peak width value is quick. The latter is most probably caused by the finite width of the amplitude of ion oscillations in the FAIMS analytical gap (the greater the $U_{d}$, the greater the width), and applying the ripple voltage is equivalent to decreasing the effective width of the analytical gap. As soon as the effective width of the analytical gap becomes comparable with the ion oscillation amplitude, peak width narrowing becomes

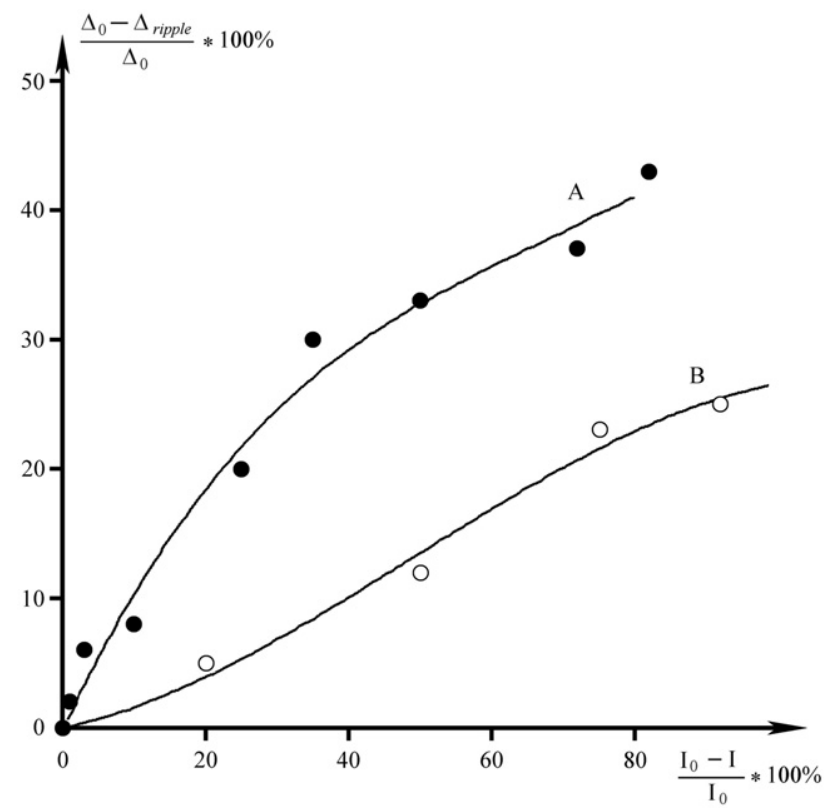

Figure 4. Reduction of the FAIMS peak width versus reduction of its intensity for protonated triamilamine ion, $\mathrm{H}^{+}\left(\mathrm{C}_{5} \mathrm{H}_{11}\right)_{3} \mathrm{~N}$. Curves $\mathrm{A}$ and $\mathrm{B}$ correspond to $U_{\text {ripple }}$ applied to the extractor electrode and the outer electrode, respectively. 


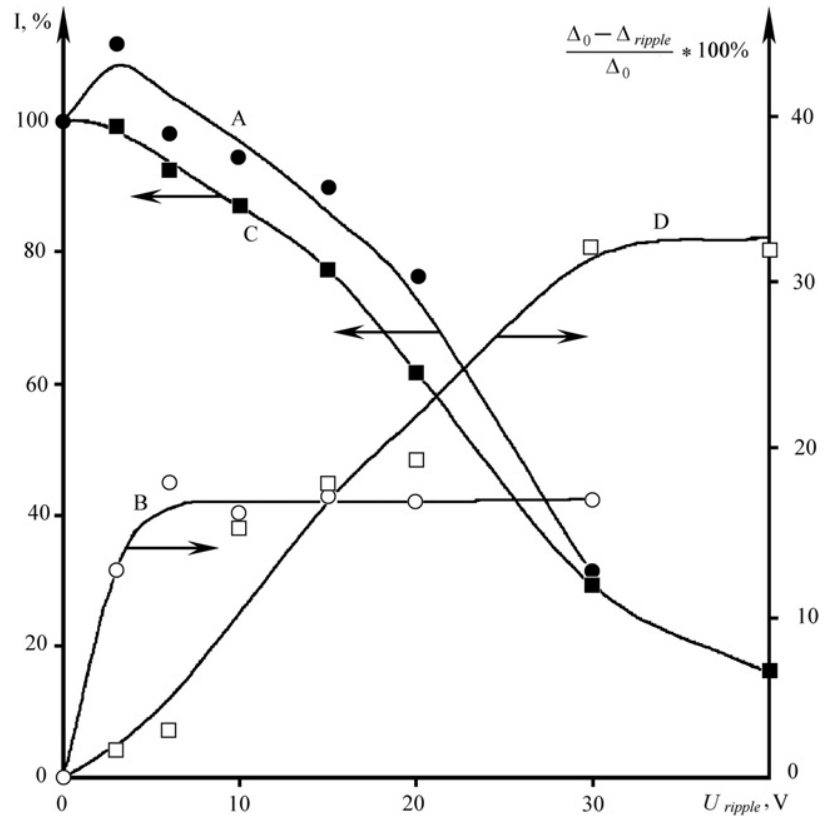

Figure 5. FAIMS signal intensity of protonated diethylamine ion, $\mathrm{H}^{+}\left(\left(\mathrm{C}_{2} \mathrm{H}_{5}\right)_{2} \mathrm{NH}\right)$, [curves $\mathrm{A}$ : filled circles and $\mathrm{C}$ : filled squares, left-hand scale] and the peak narrowing value at half-maximum, in percent (curves B: open circles and D: open squares, right-hand scale) as a function of ripple voltage, $U_{\text {ripple }}$. Curves A and B were obtained at $U_{d}=2.035 \mathrm{kV}$ and $U_{c}=-7.5$; curves $C$ and D were obtained at $U_{d}=1.57 \mathrm{kV}$ and $U_{c}=-3.5 \mathrm{~V}$. The $U_{\text {ripple }}$ was applied to the extractor electrode. The spacing between extractor and inner electrodes, $X=5.3 \mathrm{~mm}$.

impossible because the interval $\delta U_{c}$, corresponding to the ion transition at this $U_{d}$, degenerates to the unique value of $U_{c}$, and the FAIMS peak width becomes governed by other physical processes.

We managed to achieve, in many but not all of the experiments, the discontinuance of peak width reduction with increasing ripple voltage. In some experiments, the weakness of the signal intensity made it impossible to measure peak width with appropriate accuracy. However, the beginning of this process (loss of linear dependence) was observed in all of the experiments (see Figure 6).

The ultimate peak width narrowing that can be achieved by applying the ripple voltage to the extractor electrode is the most important value in characterizing the applicability limits of the method. This value depends both on device characteristics and on the properties of the analyzed compound and the carrier gas. Figure 6 shows the value of peak width as a function of applied $U_{\text {ripple }}$ for protonated ions of all of the investigated compounds for $U_{d}=2.035 \mathrm{kV}, X=5.3 \mathrm{~mm}$, i.e., for diethylamine $\left(\left(\mathrm{C}_{2} \mathrm{H}_{5}\right)_{2} \mathrm{NH}\right.$ : open squares); aniline $\left(\mathrm{C}_{6} \mathrm{H}_{5} \mathrm{NH}_{2}\right.$ : open circles); $\mathrm{N}, \mathrm{N}$-diethylacetamide $\left(\mathrm{CH}_{3} \mathrm{C}(\mathrm{O}) \mathrm{N}\left(\mathrm{C}_{2} \mathrm{H}_{5}\right)_{2}\right.$ : filled circles); $\mathrm{N}, \mathrm{N}$-diethylaniline $\left(\mathrm{C}_{6} \mathrm{H}_{5} \mathrm{~N}\left(\mathrm{C}_{2} \mathrm{H}_{5}\right)_{2}\right.$ : open diamonds); and triamilamine $\left(\left(\mathrm{C}_{5} \mathrm{H}_{11}\right)_{3} \mathrm{~N}\right.$ : filled squares). The accuracy of measuring the peak width was not high enough to correlate the narrowing effect and the properties of the compounds.
However, we have tried to approximate the experimental results by a curve of the form $\mathrm{y}=a \mathrm{x}+b \mathrm{x}^{2}$, assuming that the parameter $a$ in the equation represents the initial appearance of the effect, which is primarily determined by device characteristics, whereas the parameter $b$ (negative) characterizes the achievement of a steady value by the effect and must depend on the nature of the compound. Figure 6 illustrates this type of approximation for triamilamine, where we have obtained the maximal effect (top curve, solid line), and for $\mathrm{N}, \mathrm{N}$-diethylacetamide, where the effect was minimal (bottom curve, dashed line). The same figure shows the obtained parameters $a$ and $b$ and the approximation validity parameter $R^{2}$.

The values of parameter $a$ for these curves are very close, within $5 \%$ (1.222 and 1.2611), as for similar curves plotted for all other compounds investigated. The values of parameter $b$ differ by $\sim 70 \%(-0.0082$ and $-0.0137)$, which shows that the differences in physicalchemical properties affect the limits of peak width narrowing that can be achieved by applying $U_{\text {ripple }}$ to the extractor electrode. We should also note that $N, N$ diethylacetamide is the only amide in our investigation among several amines of different structure, and it demonstrated the minimal narrowing effect in contrast to amines that showed a similar result.

\section{Conclusions}

We have proposed and verified the idea of optimizing FAIMS performance in terms of sensitivity and resolution by applying the ripple voltage to a hemispheric electrode of ion delivery to a mass spectrometer. In this approach, the variation of ripple amplitude allows

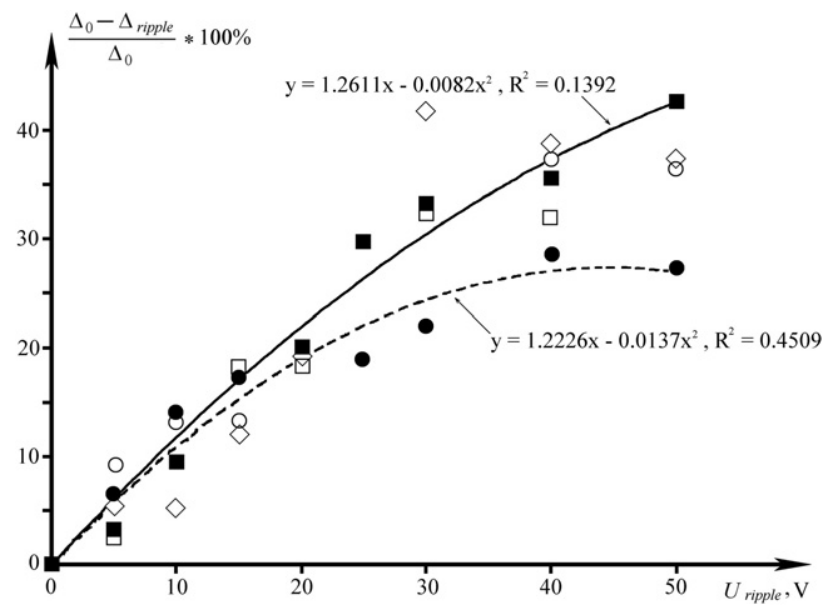

Figure 6. The peak narrowing value as a function of applied $\mathrm{U}$ for protonated ions of the compounds: diethylamine $\left(\left(\mathrm{C}_{2} \mathrm{H}_{5}\right)_{2} \mathrm{NH}\right.$ : open squares); aniline $\left(\mathrm{C}_{6} \mathrm{H}_{5} \mathrm{NH}_{2}\right.$ : open circles); $\mathrm{N}, \mathrm{N}$-diethylacetamide $\left(\mathrm{CH}_{3} \mathrm{C}(\mathrm{O}) \mathrm{N}\left(\mathrm{C}_{2} \mathrm{H}_{5}\right)_{2}\right.$ : filled circles); $\mathrm{N}, \mathrm{N}$-diethylaniline $\left(\mathrm{C}_{6} \mathrm{H}_{5} \mathrm{~N}\left(\mathrm{C}_{2} \mathrm{H}_{5}\right)_{2}\right.$ : open diamonds); triamilamine $\left(\left(\mathrm{C}_{5} \mathrm{H}_{11}\right)_{3} \mathrm{~N}\right.$ : filled squares $) . U_{d}=2.035$ $\mathrm{kV}, X=5.3 \mathrm{~mm}$. Approximations of data for triamilamine and $\mathrm{N}, \mathrm{N}$ diethylacetamide by $\mathrm{y}=a \mathrm{x}+b \mathrm{x}_{2}$ are shown by solid and dashed lines, respectively. 
more effective control of an exchange between FAIMS resolution and sensitivity compared to applying $U_{\text {ripple }}$ along the total length of the device (because the diffusion ion loss is less). A similar approach can probably be used on the other short portion FAIMS device (for example, applying $U_{\text {ripple }}$ on a short site of a cylindrical part of the device). It is useful for most current cylindrical devices, where ions traveling in the plane, orthogonal to an axis FAIMS (all commercial platforms by Thermo Fisher) and have not any spherical parts.

The peak width reduction upon application of $U_{\text {ripple }}$ does not occur linearly, and in some experiments, the peak width ceases to narrow even as the signal intensity is still decreasing. This can determine the limits of applicability of the proposed method.

On the whole, we have concluded that the idea of applying $U_{\text {ripple }}$ to the extractor electrode to decrease the time of its action on ions and reduce the diffusion loss is useful, and may be considered as a sensible approach to controlling FAIMS resolution in exchange for sensitivity.

\section{Acknowledgments}

The authors acknowledge support for this work by the Presidium of the Russian Academy of Sciences, grant no. 20.5-09, and in part by the Russian Foundation for Basic Research, project no. 07-0800,143-a.

\section{References}

1. Guevremont, R. High-Field Asymmetric Waveform Ion Mobility Spectrometry: A New Tool for Mass Spectrometry. J. Chromatogr. A 2004, 1058, 3-19.

2. Veasey, C. A.; Thomas C. L. P. Fast Quantitative Characterization of Differential Mobility Responses. Analyst 2004, 129, 198-204.

3. Krylov, E. V. Comparison of the Planar and Coaxial Field Asymmetrical Waveform Ion Mobility Spectrometer (FAIMS). Int. J. Mass Spectrom. 2003, 225, 39-51.

4. Guevremont, R.; Purves, R. W. Atmospheric Pressure Ion Focusing in a High-Field Asymmetric Waveform Ion Mobility Spectrometer. Rev. Sci. Instrum. 1999, 70, 1370-1383.

5. Guevremont, R.; Purves, R. W. Comparison of Experimental and Calculated Peak Shapes for Three Cylindrical Geometry FAIMS Prototypes of Differing Electrode Diameters. J. Am. Soc. Mass Spectrom. 2005, $16,349-362$.

6. Shvartsburg, A. A.; Tang, K.; Smith, R. D. FAIMS Operation for Realistic Gas Flow Profile and Asymmetric Waveforms Including Electronic Noise and Ripple. J. Am. Soc. Mass Spectrom. 2005, 16, 1447-1455.

7. Guevremont, R.; Thekkadath, G.; Hilton, C. K. Compensation Voltage (CV) Peak Shapes Using a Domed FAIMS with the Inner Electrode Translated to Various Longitudinal Positions. J. Am. Soc. Mass Spectrom. 2005, 16, 948-956.

8. Guevremont, R.; Purves, R. W.; Barnett, D. A.; Ding, L. Ion Trapping at Atmospheric Pressure (760 Torr) and Room Temperature with a HighField Asymmetric Waveform Ion Mobility Spectrometer. Int. J. Mass Spectrom. 1999, 193, 45-56.

9. Guevremont, R.; Ding, L.; Ells, B.; Barnett, D. A.; Purves, R. W. Atmospheric Pressure Ion Trapping in a Tandem FAIMS-FAIMS Coupled to a TOF-MS: Studies with Electrospray Generated Gramicidin S Ions. J. Am. Soc. Mass Spectrom. 2001, 12, 1320-1330.

10. Pervukhin, V. V.; Sheven, D. G. Suppression of the Effect of Charge Cloud in an Ion Mobility Increment Spectrometer to Improve Its Sensitivity. Tech. Phys. 2008, 53, 110-116.

11. Pervukhin, V. V.; Sheven, D. G. Increasing the Resolution of Ion Mobility Increment Spectrometers Using the Ripple Voltage. Tech. Phys. Lett. 2008, 34, 977-980.

12. Pervukhin, V. V. Effect of Additives in a Carrier Gas on the Behavior of Ions in an Ion-Mobility Increment Spectrometer. J. Anal. Chem. 2008, 63, 1182-1190.

13. Pervukhin, V. V.; Ibragimov, R. R.; Moralev, V. M. Mass Spectrometer Based on the MX-7304 Analyzer with Direct Ion Injection from the Atmosphere. Instrum. Exp. Tech. 1997, 40, 700-701. 